Estética de la irrupción. Activismo y performance en Las Yeguas del Apocalipsis (Chile 1987-1993)

Aesthetics of the irruption. Activism and performance in Las Yeguas del Apocalipsis

Fátima Vélez Giraldo

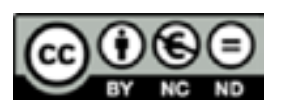

Esta obra está bajo una licencia Creative Commons Reconocimiento-No comercial-Sin Obra Derivada 
Artículos

\section{Estética de la irrupción. Activismo y performance en Las Yeguas del Apocalipsis (Chile 1987-1993)}

\section{Aesthetics of the irruption. Activism and performance in Las Yeguas del Apocalipsis}

Fátima Vélez Giraldo ${ }^{1}$ City University of New York Nueva York, Estados Unidos

Recibido: 14 de febrero del 2018 Aprobado: 16 de mayo del 2018

\section{Resumen}

Este trabajo examina los mecanismos estéticos y políticos de uno de los primeros grupos artísticos que politizaron la crisis del VIH/sida en Latinoamérica: el colectivo Las Yeguas del Apocalipsis, conformado en 1987 por Pedro Lemebel y Francisco Casas. A partir de algunas de las obras más significativas del colectivo se explorará la manera en que estas intervenciones dialogan con el activismo cultural, planteado por Douglas Crimp, con el fin de acabar con la epidemia. En el caso de Las Yeguas del Apocalipsis el activismo asume una forma radical que hace posible desde la corporalidad una lucha política, un debate por la salud, la diversidad, pero también una reivindicación de los sujetos marginales. A través del performance esta politización pone en jaque la forma en que se habla en público de la sexualidad y, al mismo tiempo, integra una aguda reflexión sobre dictadura, postdictadura y neoliberalismo, y el control de estas fuerzas sobre los cuerpos no heteronormativos.

Palabras clave: sida; activismo cultural; subjetividades; corporalidades; performance; disidencia sexual

1 Estudiante segundo año de Doctorado en Latin American, Iberian and Latino Cutlures por Graduate Center, City University of New York, New York. Maestría en Escritura Creativa por la Universidad de Nueva York. Correo electrónico: fvelez@gradcenter.cuny.edu 


\begin{abstract}
This paper examines the aesthetic and political mechanisms of one of the first artistic groups that politicized the HIV/ AIDS crisis in Latin America: Las Yeguas del Apocalipsis, formed in 1987 by Pedro Lemebel and Francisco Casas. I will focus on the way in which their interventions dialogue with cultural activism, a term raised by Douglas Crimp in order to end the epidemic. Based on some of the most significant works of the collective, this paper explores the way in which activism assumes a radical form thorugh corporality, which likewise raises a debate about health, diversity, and a vindication of marginal subjects. Through the particular use of performance this politicization puts in check the way in which sexuality is spoken in public, and at the same time, integrates a sharp reflection on dictatorship, post-dictatorship, neoliberalism, and the control of these forces over non-heteronormative bodies.
\end{abstract}

Keywords: AIDS, cultural activism, subjectivities, corporalities, performance, sexual dissidence. 
Estética de la irrupción.

Artículos

Activismo y performance en Las Yeguas del Apocalipsis (Chile 1987-1993)

Y miré, y he aquí un caballo blanco;

y el que lo montaba tenía un arco;

y le fue dada una corona, y salió venciendo,

y para vencer

(Apocalipsis 6: 2)

\section{Activismo cultural}

En 1987, Douglas Crimp, activista y crítico de arte norteamericano, dice sobre la crisis del VIH/sida y lo que él considera debe ser la posición de los artistas frente a esta: "no necesitamos trascender la epidemia, necesitamos acabarla" (1998, p. 113). Con estas declaraciones, publicadas en la edición de la revista October (que luego haría parte del primer libro de crítica sobre el sida, Aids: Cultural Analysis, Cultural Activism de 1998), dedicada a una reflexión por parte de la comunidad artística y académica contra la enfermedad, Crimp pone en el centro del debate la noción de activismo cultural. El activismo cultural, además de ser un pilar fundamental en la lucha contra el $\mathrm{VIH} /$ sida, es a la vez una oportunidad para otro tipo de luchas de la disidencia sexual y su reconocimiento social que, en América Latina, no se insertaron bajo el amparo de los ideales de izquierda (como lo soñó, por ejemplo, El Frente de Liberación Homosexual Argentino o el Movimiento Homosexual Chileno), ni del acomodo proporcionado por el desarrollismo neoliberal -implícito en el discurso de la democracia- sino bajo dinámicas propias, que, como señala Gabriel Giorgi, están ancladas en "la promesa de la vida común; la vida que no sea siempre ya propia, apropiable, privatizable -y por lo tanto, capitalizable, privatizable, objetivable" (2014, p. 120). Estas dinámicas ponen de manifiesto una cuestión sobre el cuerpo y la diversidad sexual. Y es que el surgimiento y la expansión del virus del $\mathrm{VIH} /$ sida, al menos en el mundo occidental, en un momento en que las disidencias sexuales intentaban conseguir reconocimientos importantes, constituyó una suerte de hendidura que permitió el resurgimiento de ideas conservadoras y rígidas en torno a la disidencia, ideas que habían sido menguadas durante la liberación sexual de las décadas de 1960 y 1970. La creencia generalizada de que el sida era una enfermedad que afectaba mayoritariamente a los hombres homosexuales constituía el despertar de una idea estereotípica de la homosexualidad como conducta "inmoral", pero ahora el énfasis no recaía únicamente en los cimientos morales de una sociedad; con el sida, la homosexualidad se convertía en una amenaza contra la vida de las personas. Por otra parte, parecía que el virus desplazaba la lucha política de la disidencia por una lucha por sobrevivir, por el "sálvese quién pueda". Algunos escritores como Reinaldo Arenas, Néstor Perlonguer y Pedro Lemebel, los tres desde ópticas distintas, todas desesperanzadoras, apocalípticas, ven en el virus un ángel exterminador que llega a poner fin a la posibilidad de la emancipación de la disidencia sexual que tanto habían anhelado.

ESCENA. Revista de las artes, 2019, Vol. 78, Núm. 2 (enero-junio), pp. 92-106 


\section{La retórica apocalíptica}

Pero mientras en Estados Unidos, específicamente en Nueva York y en San Francisco, estaban sucediendo manifestaciones artístico-políticas como las del colectivo ActUp (Aids Coalition to Unleash Power [la coalición del sida para liberar el poder]), ¿cómo se estaba asumiendo la expansión de la epidemia en Latinoamérica en la década de 1980 y principios de 1990? En tiempos de guerras civiles y dictaduras militares, ¿cuál fue la posición de la comunidad artística frente a una enfermedad que, se creía, afectaba a una parte de la población que era preferible ignorar o permitir su eliminación a través de un medio aparentemente "natural"?

Desde la retórica apocalíptica tomará forma, podría decirse que redentora, uno de los primeros grupos artísticos que visibilizaron -y de esta manera politizaron- la crisis del sida en Latinoamérica: Las Yeguas del Apocalipsis. El colectivo, conformado en Chile en 1987 por los artistas y escritores Pedro Lemebel y Francisco Casas, hace parte de una secuencia histórica de artistas que accionaron con sus cuerpos políticas de resistencia en el espacio público, como aquellas contra el régimen dictatorial chileno realizadas por CADA (Colectivo Acciones de Arte) y las intervenciones de los artistas Francisco Copello y Carlos Leppe, los primeros en realizar performances "homosexuales" que "marcaron el imaginario urbano chileno a mediados de la década de los años ochenta" (Blanco, 2011, p. 14). Fernando Blanco se refiere a las yeguas como "colectivo de arte homosexual". Sin embargo, me parece complicado llamarlo de esta manera porque las intervenciones de Las Yeguas retuercen hasta tal punto la cuestión de la homosexualidad que vuelven problemático la manera de referirse a ella. Como dice Monsiváis en uno de los artículos recopilados por Blanco sobre Lemebel: "lo gay no es la identidad artística sino la actitud contigua que afirma una tendencia cultural y un movimiento de conciencia" (2001, p. 39).

Las Yeguas del Apocalipsis incorporan la problemática del sida en trabajos como "Lo que el sida se llevó" (1989); "Estrellada" (1989); "Casa particular" (1989); "Cuerpos contingentes" (1990); "Homenaje a Sebastián Acevedo" (1991) y "Ejercicio de Memoria” (1997). En este trabajo me detendré en la manera en que las intervenciones de Las Yeguas dialogan con lo planteado por Crimp y sus incitaciones a la comunidad -tanto artística como disidente- de acabar con el VIH/sida por medio del activismo cultural. Cómo el activismo asume, en el caso de Las Yeguas, una forma radical, que, contrario a las profecías del propio Lemebel sobre el $\mathrm{VIH} /$ sida como una fuente de exterminio de la disidencia sexual, hace posible desde la corporalidad una lucha política, un debate por la salud, la diversidad y, también, una reivindicación de los sujetos marginales. Me concentro en la manera en que a través del performance travesti, la politización propuesta por Las Yeguas pone en jaque la forma en 
Estética de la irrupción.

Artículos

Activismo y performance en Las Yeguas del Apocalipsis (Chile 1987-1993)

que se habla en público de la sexualidad y, al mismo tiempo, integra una serie de inversiones que permiten otras miradas hacia la dictadura, postdictadura y neoliberalismo, y el control de estas fuerzas sobre los cuerpos no heteronormativos.

\section{La travesti como figura radical}

En el caso de Las Yeguas, específicamente, el activismo asume en la figura de la travesti un gesto radical a través del cual opera. Dice Lembel al respecto de su interés por la travesti:

Pongo mi corazón escritural junto a la travesti por una razón social. El SIDA aniquila mucho más a los sectores más desprotegidos, tal como la tuberculosis y la sífilis eliminaron a los pueblos primitivos. En el mundo travesti prostibular es donde el SIDA, provoca mayores llagas, y donde no hay ni se ejercita ninguna prevención (citadi en Iñiguez, 1 de octubre de 1996).

Si la travesti es, como dice Lemebel, precisamente el sujeto receptor "donde el sida provoca mayores llagas", la conversión de esta vulnerabilidad en la cara de una potencia política constituye una inversión del imaginario de la travesti como figura sexualizada hacia la travesti como figura radical de una radicalización. Las Yeguas del Apocalipsis hacen de la travesti un símbolo, "una especie en vía de extinción", cuya función es desarticular las fuerzas del homosexual masculinizado yanqui, el cual es, según Las Yeguas, al mismo tiempo lo que provoca el contagio, no solo del cuerpo individual, sino del cuerpo social. Es decir, desde la perspectiva del colectivo, la travesti se instituye como una especie de "guerrera" que debe militar para impedir la propagación del homosexual masculinizado; figura "importada", extranjera, responsable del germen de la enfermedad y de su expansión en territorio antes virgen. Esta politización a través del performance travesti integra una aguda reflexión sobre las contradicciones entre

liberalismo político y Derechos Humanos, la falta de garantías ciudadanas propuestas por la democracia liberal, o las tensiones entre apertura e individualismo en el consumo, por un lado, y la estricta regulación social y reproducción o agravamiento de las diferencias de clase, por otro (Blanco, 2004, p. 13).

En sus primeras performances: "Coronación de espinas" (1988) y "Refundación de la Universidad de Chile" (1988), la irrupción fue literalmente un modus operandi. Así, irrumpieron ostentosamente en la ceremonia en la que el poeta Raúl Zurita recibía el premio Pablo Neruda; o irrumpieron desnudos en la Universidad de Chile montados sobre una yegua blanca. Posteriormente, irrumpieron en la exposición Cuerpos Contingentes de las escritoras Diamela Eltit y Lotty Rosenfield, vestidas como pacientes terminales de sida. Este irrumpir en circuitos culturales ya politizados fue una manera de inscribir los cuerpos del sida dentro de la esfera estético-política de otros cuerpos marginados como aquellos de los desaparecidos por la dictadura chilena. Con sus acciones, Las Yeguas irrumpen a galope en la escena pública para

ESCENA. Revista de las artes, 2019, Vol. 78, Núm. 2 (enero-junio), pp. 92-106 
incomodar, desconfigurar y, al mismo tiempo, señalar el control de las fuerzas políticas sobre los mecanismos culturales. Con su irrupción, Las Yeguas inscriben cuerpos no solo marginados, sino también no heteronormativos. Como dice Blanco: "por casi una década se mantendrían en el ojo del huracán como activistas insobornables en la resistencia estético-urbana de la ciudad sitiada/sidada de la dictadura, transformada progresivamente a través de 17 años del régimen filial macabro del capital nacional” (Blanco, 2004, p. 45).

De esta manera, Las Yeguas del Apocalipsis despliegan un complejo aparato de transgresión en el restringido espacio público de la sociedad chilena en transición hacia la democracia. Un espacio público, que, si se piensa, es también un escenario en construcción, en el que la figura de la travesti está llena de sentido. Desde el punto de vista de Las Yeguas, este escenario se traza como un horizonte de posibilidad, un campo de resignificaciones por hacerse, en el que, sin embargo, no es posible anular la memoria de lo acontecido durante la dictadura, en especial, la violencia brutal de los militares sobre los cuerpos. Anulación que no solo se produce en el cuerpo físico, en el caso de los desaparecidos, sino también en la posibilidad de la diferencia y la diversidad, que en el campo de la sexualidad homogenizó y legitimó al homosexual reprimido, en terrenos como lo militar, o en círculos políticos, pero siempre detrás del clóset, simulando, fingiendo, ocultando. Dicen Las Yeguas en uno de sus manifiestos:

Mira, todos los homos somos diferentes. El asunto yeguas es un imaginario colectivo. Es el sida, la trompeta del apocalipsis, el fin de siglo. Llenamos un espacio mórbido, todos estaban ansiosos que apareciéramos: llenamos la necesidad épica de la gente, pero nosotros somos otra cosa, filo con el mito (Salas, 1 al 8 de mayo de 1989, p. 27).

"Filo con el mito", irrumpir en un espacio donde el orden está dado o por la desaparición o por la virtualidad espectacular de los medios de comunicación, donde se muestra lo espectacular normativizado o lo no normativizado como espectacular, pero la norma para todo aquello que no encaja dentro de lo visible es esconder, desaparecer, disimular. En este sentido, los medios de comunicación han ejercido como fachada, o como carnada de la atención del imaginario popular. He ahí, como señala Blanco, la necesidad de Las Yeguas

de restituir una identidad y una conciencia de clases a los millares de compatriotas alienados por la venda mercantil que ha adelgazado la memoria hasta los límites mismos de la pantalla televisiva. Incluso nuestra historia ha devenido objeto suntuario de consumo para los ciudadanos partícipes de una democracia articulada en y por los medios de comunicación (2004, p. 81).

Es de notar que la performance de la travesti de Las Yeguas opera con los mismos mecanismos de aquello a lo que el colectivo se opone. De esta manera, Las Yeguas travisten la espectacularidad normativizada de los medios en una espectacularidad travesti que 
permite radicalizar la espectacularidad y convertirla en materia política. Es así como en muchos de sus performances, las Yeguas se apropian de las figuras populares de las estrellas de Hollywood, como Marilyn Monroe y Rita Hayworth, para controvertir lo que ellas simbolizan en el imaginario popular, para subvertir y plantear el travestismo como una estética impropia que permitirá otras posibilidades desde las cuales vivir en disidencia. Se trata de un travestismo que opera no solo como hombres que se disfrazan de mujeres, sino como hombres homosexuales que asumen la figura de las estrellas más representativas de Hollywood y hacen de su cuerpo un territorio de disenso entre géneros, mundos, imaginarios; un territorio de subversión desde el cual se articulará la irrupción. Dice Llanos al respecto:

Mujeres erráticas, desenfadadas producidas para la satisfacción de los deseos y fantasías masculinas, desde las actrices hispanas y latinoamericanas, como Sara Montiel y María Félix (las mismas que van a inspirar más de una performance de Las Yeguas del Apocalipsis, entre ellas "Estrellada"), hasta las declinaciones anglosajonas de divas cantantes de celuloide y tablas, como Marilyn Monroe y Madonna. La historización de su afán imaginario recoge como tercer soporte de sus juegos eróticos textuales a los modelos sociales junto con los colectivos políticos de mujeres que lucharon contra la dictadura militar patriarcal. De este modo, el cronista reflexiona sobre la legitimación cultural de los modelos femeninos funcionales a los espacios homosociales del autoritarismo militar, eclesiástico e ideológico, a la vez que su alter ego textual, la Loca, los extrema hasta el delirio en su teatralización para mostrar el carácter simbólico de las ofertas y de las fantasías de los individuos, iluminando las consecuencias nefastas del destino de lo femenino en mundos fantaseados para los hombres por los propios sujetos masculinos (Llanos, 2010, p.182).

\section{El cuerpo interruptor}

Las Yeguas irrumpen en el escenario del deseo masculino a partir de la transgresión travesti entre lo masculino-femenino, pero también, desde otra forma transgresora: el cuerpo animal. Así, este par de yeguas se apropia del escenario público para trazar un vínculo con lo visible, con lo material y crear una memoria animalizada; sustituir la desaparición por una imagen vívida de la irrupción. Sin ser invitadas, pero lo suficientemente producidas para causar estruendo en el pensamiento normativo, cuya capacidad de acción y reflexión está obnubilado entre la devastación de la dictadura y la promesa del cambio que vendrá y que está anunciada como promesa eterna a través de los medios. Y la irrupción, que ya es de por sí una transgresión en una sociedad donde los buenos modales priman, donde nadie entra sin ser invitado está, sin embargo, dada por un referente arraigado al catolicismo: el apocalipsis; es la irrupción por antonomasia del imaginario normativizado por la religión y las conductas morales. Pero acá, en vez de hablar de jinetes, se habla de 
"yeguas"; no solo hay un intercambio subversivo del jinete por el animal, sino del sujeto masculino por el animal femenino. El travestismo está operando como decodificador desde la denominación del colectivo.

Por otra parte, es de notar el hecho de que las Yeguas adopten el performance como canal estético. Es esta ya una operación que, si nos atenemos a las reflexiones de Judith Butler, en diálogo con los estudios del performance de Diana Taylor sobre el género como una construcción performática y el performance como mecanismo que descentraliza la hegemonía masculina heteronormativa, ponen en escena la manera en que tanto el cuerpo, como los aparatos en los que se inscribe -género, identidad, subjetividad, vínculos- son construcciones que, como tal, son susceptibles a una deconstrucción. Acerca de lo que el performance como medio puede aportar a una manera de hablar del cuerpo como espacio público dentro de la crisis del sida, Diana Taylor señala:

Las conductas de sujeción civil, resistencia, ciudadanía, género, etnicidad, e identidad sexual, por ejemplo, son ensayadas y reproducidas a diario en la esfera pública. Entender este fenómeno como performance sugiere que performance también funciona como una epistemología. Como práctica in-corporada, de manera conjunta con otros discursos culturales, performance ofrece una determinada forma de conocimiento. La distinción como (performance) subraya la comprensión de performance como un fenómeno simultáneamente "real" y "construido", como una serie de prácticas que aúnan lo que históricamente ha sido separado y mantenido como unidad discreta, como discursos ontológicos y epistemológicos supuestamente independientes (agosto, 2007).

La manera en que el género se establece no como algo esencial y, por lo tanto, inmodificable, sino como algo impuesto, quizás un sueño, quizás un performance para entenderlo en términos de Judith Butler, como repetición de una serie de normas que se repiten hasta el olvido de la convención que le da origen a las repeticiones; el género como una serie de normas que se "naturalizan" de tal forma en nuestra vida cotidiana que es difícil pensarlas como algo externo e impuesto (Butler, 2002, p. 18). Precisamente esas convenciones que se repiten una y otra vez hasta volverse norma son las que se ponen en evidencia en el mecanismo irruptivo de Las Yeguas, en el cual, al reforzar hiperbólicamente los roles establecidos, se desajusta y desmantela que el género impone una idealización fallida que provoca que siempre actuemos alrededor de la normatividad. Es pues en la exaltación de esos valores normativos, en su exageración, en la brecha del humor y la incomodidad y el desconcierto que se abre un túnel de esperanza: en la posibilidad de subversión y la desestabilización del género que permite el travestismo yegua, en esta desfamiliarización, aparecen subjetividades independientes del género, si bien inscritos dentro de códigos y normas sociales, capaz de hacerles frente. 
Estética de la irrupción.

Artículos

Activismo y performance en Las Yeguas del Apocalipsis (Chile 1987-1993)

La estética de la irrupción coincide con el performance como medio artístico. Pero hay que tener en cuenta, como dicen los editores de la página web que recoge el archivo de Las Yeguas del Apocalipsis, que

La intensificación del cuerpo presente dotaba la intervención de Lemebel y Casas de un carácter de acontecimiento, lo que permite identificar su producción con las claves de la performance. Sin embargo, decir performance significaba una toma de posición, especialmente entre productores que, desde América Latina, buscaban crear conceptos propios cuestionando los centros internacionales del arte. Las Yeguas del Apocalipsis tuvieron una postura crítica frente al sistema artístico y desconfiaban de sus rótulos y modelos de validación, de modo que entraban y salían tácticamente de la categoría performance. De hecho, no se inscribieron en el relato de ninguna tradición artística a literaria, como tampoco se afiliaron a ninguna corriente de aquella época. Consecuentemente, su práctica se fue desplazando fuera de las instituciones del arte, privilegiando lugares alternativos y el espacio público de la ciudad (Las Yeguas del Apocalipsis, 2015)

Cada uno de estos performances es irrepetible y cada vez se radicalizan más. Asumir una forma distinta surte el efecto de provocación que conduce a la acción y a la formación de un espacio para los sujetos no normativos, un espacio de comunidad y reconocimiento, que es lo que busca en efecto el activismo cultural. Dice Lemebel al respecto:

A nadie se le olvidan Las Yeguas del Apocalipsis. A nadie se le olvidan algunas irrupciones escandaleras que yo he hecho. Pero también, por sobre eso, algunas minorías tienen que pasar por esa irrupción para inscribirse en la historia cultural del país, en el medio pacato, moralista, por no decir hipócrita, que hace pasar este tipo de tema por esa fanfarria de espectáculo, de frivolidad (Lemebel en Masiello, 2001, p. 10).

El operar de Las Yeguas constituye un irrumpir del cuerpo, pero, al mismo tiempo, una inscripción literal en el espacio público. Por ejemplo, en el performance "Estrellada" de 1989, un programa de intervenciones plásticas en el espacio urbano en el Instituto Chileno Francés de Cultura, Las Yeguas intervinieron la calle San Camilo, centro activo de prostitución travesti de Santiago. Pintaron sus cuerpos como si fueran robots a blanco y negro; utilizaron focos de luz que remitían a un set cinematográfico y, semidesnudas, trazaron estrellas fosforescentes en el pavimento en negativo y positivo. Así, ambientaron la calle al estilo del "Walk of fame" de Hollywood. Simultáneamente, desde la ventana de uno de los prostíbulos, proyectaron diapositivas de la sesión fotográfica "Lo que el Sida se llevó", una exposición en la que Las Yeguas aparecían vestidas como las divas de Hollywood. En las fotografías, tomadas por el fotógrafo Mario Vivado, Lemebel y Casas representaron a distintas figuras culturales de Hollywood como Marylin Monroe, Buster Keaton y las hermanas de "La Casa de Bernarda Alba" de García Lorca. Utilizaron prendas del mercado persa y de amigas travestis (muchas de ellas con el virus del $\mathrm{VIH}$ ). El corte estético de estas prendas

ESCENA. Revista de las artes, 2019, Vol. 78, Núm. 2 (enero-junio), pp. 92-106 
hacía eco del glamour de la edad de oro de las divas de Hollywood. Esa noche del 25 de noviembre de 1989 coincidió con el cumpleaños de Pinochet. Hubo un apagón general que hizo más visibles las estrellas en el espacio público y que habían sido prendidas con fuego. De esta manera, uno de los barrios más marginados de Santiago brillaba con luz propia.

Entre la coherencia y la ambivalencia, el cuerpo cambiante y no articulable es un espacio siempre en discusión. Sin embargo, tal vez porque en las sociedades disciplinarias la no articulación es un síntoma de caos, nuestros cuerpos están sujetos a controles y, en este sentido, su inscripción dentro de lo social y su inferencia en el espacio público están condicionados. Tal vez por eso y porque los sometimientos políticos han sido más directos en América Latina ${ }^{2}$, las intervenciones del cuerpo en el espacio público -esa relación material y visible entre cuerpo y calle, entre cuerpo y colectivo- ha sido un canal de articulación de luchas contra los regímenes de poder, contra la sociedad disciplinaria, una preocupación que resuena con lo planteado por Rancière, cuando señala:

El "más que eso" del arte y el "nunca del todo" de la democracia, lo siempre incompleto de la demanda feminista, figuran el litigio de los cuerpos y los nombres "sin lugar". Estos cuerpos y nombres "fuera de lo suyo propio", lo sabe el feminismo, ocupan cualquier margen de descentramiento para reclamar contra las jerarquías oficiales de distribución del valor y la representación culturales (2006, p. 53).

De esta manera, "los cuerpos y nombres fuera de lo suyo propio" están llamados a provocar subjetividades constituidas en relación con lo común, que puedan preservarse en su subjetividad, sin triturar su relación con lo común. Hay que pensar en formas que no se dejen capturar por esas formas normativas de lo privado (lo capitalizable) y lo público (propiedad del Estado). Cuando se habla de una posibilidad de "unión" de la disidencia, cuando se habla de una lucha revolucionaria, se habla de cómo la disidencia tiene en sus manos la posibilidad de transgredir para provocar espacios, lenguajes, no instituciones, sino instancias de lo común. La ciudad, el cuerpo, el género son lugares de disputa en torno a lo común. El rescate de lo común resuena con lo planteado por De Certau, cuando dice:

2 Me refiero a menos virtuales que, por ejemplo en Estados Unidos, donde los poderes provienen de corporaciones sin rostro, donde la invisibilidad del poder hace que los mecanismos de resistencia sean inútiles, donde se las han arreglado para hacerse tan descoporalizados que las resistencias solo pueden ser igual de invisibles, como las de los hackers, que no podemos ejercer ciudadanos del común con nuestros propios cuerpos. Las performances corporales se han hecho inofensivas en tiempos de hackers y terrorismo. Habría que pensar cómo inscribir al cuerpo de nuevo como canal político de resistencia en oposición al cuerpo invisibilizado o al cuerpo arma de destrucción masiva.

ESCENA. Revista de las artes, 2019, Vol. 78, Núm. 2 (enero-junio), pp. 92-106 
Estética de la irrupción.

Artículos

Activismo y performance en Las Yeguas del Apocalipsis (Chile 1987-1993)

En la coyuntura presente de una contradicción entre el modo colectivo de la administración y el modo individual de una reapropiación, esta cuestión resulta sin embargo esencial, si se admite que las prácticas del espacio tejen en efecto las condiciones determinantes de la vida social. Quisiera seguir algunos procedimientos -multiformes, resistentes, astutos y pertinaces- que escapan a la disciplina, sin quedar, pese a todo, fuera del campo donde ésta se ejerce, y que deberían llevar a una teoría de las prácticas cotidianas, del espacio vivido y de una inquietante familiaridad de la ciudad (2000, p. 108).

Si bien performances como los de Las Yeguas del Apocalipsis no están inscritas dentro de lo que llamaríamos "practicas cotidianas", parto del supuesto de que las "prácticas" performáticas, como las realizadas por el colectivo, precisamente apuntan a que no hay una práctica más cotidiana y, en este sentido, más "común" que la relación que establecemos con nuestros cuerpos como canales de conexión entre nuestros espacios interiores y subjetivos; y nuestros espacios exteriores o colectivos. Los cuerpos del sida, en tanto salidos de control, para el sujeto, para la sociedad, son zona de ambivalencia, de desarticulación entre lo subjetivo y lo colectivo, también territorios para señalar contradicciones. No extraña que el sida se haya convertido en una esfera de señalamiento de una cantidad de contradicciones sociales y políticas. De esta manera, la forma en que, por ejemplo, una disidencia se congrega para hacerle frente a una crisis devastadora para su propia posibilidad de comunidad, esa congregación hace mucho más que luchar contra el sida; señala, por ejemplo, un punto de intersección entre cuerpo, género, identidad, política y estética; la manera en que la enfermedad, que se desarrolla en campos privados e íntimos, como el cuerpo y la sexualidad, termina siendo, como lo plantea Butler, una crítica ante la regulación del Estado en la decisión de qué cuerpos se protegen y cuáles no (por ejemplo, el hecho de que se proteja al feto no nacido y no se protejan las vidas de estas miles de personas jóvenes portadoras del virus), políticas morales, de domesticación social. Y en el caso de Las Yeguas y de lo que se articula en las crónicas de Lemebel, esto se lleva a instancias más radicales, hasta el punto de que para Lemebel, sida y neoliberalismo provienen del mismo mal. Dice Lemebel:

Mucho antes de estas regalías, la foto de las locas en ese Año Nuevo se registra como algo que brilla en un mundo sumergido. Todavía es subversivo el cristal obsceno de sus carcajadas, desordenando el supuesto de los géneros. Aún, en la imagen ajada, se puede medir la gran distancia, los años de la dictadura que educaron virilmente los gestos. Se puede constatar la metamorfosis de las homosexualidades en el fin de siglo; la disfunción de la loca sarcomida por el sida, pero principalmente diezmada por el modelo importado del estatus gay, tan de moda, tan penetrativo en su tranza con el poder de la nova masculinidad homosexual. La foto despide el siglo con el plumaje raído de las locas aún torcidas, aún folclóricas en sus ademanes ilegales. Pareciera un friso arcaico donde la intromisión del patrón gay todavía no había puesto su marca (Lemebel, 1995, p. 22).

ESCENA. Revista de las artes, 2019, Vol. 78, Núm. 2 (enero-junio), pp. 92-106 
Las Yeguas del Apocalipsis, mediante mecanismos teatrales que se impregnan en el cuerpo como el maquillaje y el vestuario, esculpieron en la gestualidad y performancia travesti, a los muertos, tanto de la dictadura como del sida. Travestida la desaparición por la irrupción, bajo los efectos del maquillaje y el disfraz, así los muertos desaparecidos y disidentes, las muertas locas, unidas por una misma causa bajo el maquillaje y el vestuario y las danzas populares de la travesti. Bajo la figura, a la vez material de labios rojos y prendas, en su mecanismo conjugador es, al mismo tiempo, inapropiable porque no corresponde a las lógicas del control normativo. La travesti es una figura a través de la cual también los muertos pueden hablar y bailar. En esta ambivalencia de la figura de la travesti que resuena con la ambivalencia del cuerpo contagiado, se articulan, al mismo tiempo unas lógicas de afecto, solidaridad y cuidado que problematizan la idea neoliberal de un "yo" y la noción homofóbica de un "ellos" y logran articulan un "nosotros". Lo que más destaco de ese nosotros es el imaginario instalado por las Yeguas bajos figuras de las divas de Hollywood hechas travestis que invocaban lo mortuorio, como en el performance "Estrellada II" o las divas travestis que cantan tango en los burdeles, como en "Casa particular", es que de ninguna manera están convocando la unión de la disidencia para exigir derechos normativos. Al contrario, como apunta Monsiváis sobre el proyecto de Lemebel,

¿Normalizarse a través de la provocación? A Lemebel lo que menos le incumbe es la normalidad, defiende sus particularismos (si lo quieren llamar identidad no se opone), habla a nombre de un colectivo, la familia ampliada, y pierde y recupera el plural y es el nosotros que se desliza por el mar de colguijes y afeites y plumas, de chistes imprevisibles y canciones inevitables y chismes que si son buenos merecen una vitrina bien iluminada y sátiras que el destinatario, lo quiera o no, incorpora a sus gestos más íntimos (2001, p. 32).

Un nosotros que está entre lo femenino y lo masculino, entre los vivos y los muertos, entre lo animal y lo humano, entre el sujeto y lo colectivo; la travesti encarna la ambivalencia de un entre, que también apunta a la transición, pero que no la deja como espacio para perpetuar un status quo de la normativización de los reprimidos o los desaparecidos, sino de la provocación, de la irrupción, de la diferencia. La irrupción de la travesti es una manera de visibilizar y movilizar los regímenes represivos y tranzarlos por otros escenarios, podría decirse que más propios. Sin embargo, tal vez haya un halo, un riesgo, en el discurso de poner a las travestis, a las locas, como las formas más "puras" del homosexual. En la crítica contra el neoliberalismo de Las Yeguas y de Lemebel, en particular, tal vez, como afirma Giorgi, surje una retórica de una matriz regional; un imaginario de un interior puro, inmune, que, como efecto del contagio, produce una retórica anticolonial que repone imaginarios de lo local inmunizado antes de la invasión. Sin embargo, sin dejar de lado las reflexiones de Giorgi, podemos pensar que lo que activan Lemebel y Casas a través del cuerpo travesti, queda como latencia, potencialidad que pensadores queer como José Esteban Muñoz desarrollan en 
textos como Cruising Utopia. De esta manera, con la figura de la travesti, tal vez Las Yeguas articulan lo que Leehla Gandhi, desde la crítica postcolonial, denomina "comunidades afectivas" o lo que Hélène Cixous llama "alianzas íntimas", formas de relacionarnos que desafían formas de pertenencia estéticas, de género, políticas, ideológicas para hacerle frente a la enfermedad y que son enclaves de articulación que, en nuestros días, pueden darle nuevos sentidos a la idea de lo común como un escenario de subjetividades compartidas.

\section{Referencias}

Blanco, F. (2004). Reinas de otro cielo: modernidad y autoritarismo en la obra de Pedro Lemebel. Santiago: LOM.

Blanco, F. \& Poblete, J. (Eds.). (2011). Desdén al infortunio. Sujeto, comunicación y público en la narrativa de Pedro Lemebel. Santiago: Cuarto Propio.

Blanco, F. (2010). De los ideales colectivos. Sentimentalismo de la primera persona. En Fernando Blanco y Juan Poblete (Eds.), Los Destinos de la Irreverencia. Fisura, sujeción y esfera pública en Pedro Lemebel. Santiago: Cuarto Propio.

Butler, J. (2002). Cuerpos que importan. Sobre los límites materiales y discursivos del sexo. Buenos Aires: Paidós.

Cixous, H. (1976). The Laugh of the Medusa (Trad. K. Cohen y P. Cohen). Signs, (1), 875- 93.

Crimp, D. (Ed). (1998). AIDS: Cultural analysis, cultural activism. An October book. Cambridge: MIT Press.

De Certeau, M. (2000). Andares de la ciudad y Relatos de espacio. En La invención de lo cotidiano, el oficio de la historia (Vol. 1). México D. F: Universidad Iberoamericana.

Gandhi, L. (2006). Affective Communities: Anticolonial Thought, Fin-de-Siècle Radicalism, and the Politics of Friendship (Politics, History, and Culture). Durham: Duke University Press.

Giorgi, G. (2004). Sueños de exterminio. Homosexualidad y representación en la literatura argentina contemporánea. Buenos Aires: Beatriz Viterbo Editora.

Giorgi, G. (2014). Formas Comunes. Animalidad, cultura y Biopolítica. Buenos Aires: Eterna Cadencia.

Iñiguez, I. (1 de octubre de 1996). Entrevista con Pedro Lemebel: Pecar por ser diferente. La Nación.

Lemebel, P. (1995). Loco Afán. Crónicas del sidario. Santiago: Cuarto propio.

Llanos, B. (2010). Esas locas madres de Pedro Lemebel. En Fernando Blanco y Juan Poblete 
(Eds.), Los Destinos de la Irreverencia. Fisura, sujeción y esfera pública en Pedro Lemebel. Santiago: Cuarto Propio.

Masiello, F. (2001). El arte de la transición. Buenos Aires: Norma.

Monsiváis, C. (2011). Pedro Lemebel: "yo no concebía cómo se escribía en tu mundo raro" o del barroco desclosetado". En Fernando Blanco y Juan Poblete (Eds.), Desdén al infortunio. Sujeto, comunicación y público en la narrativa de Pedro Lemebel. Santiago: Cuarto Propio.

Muñoz, J. E. (2009). Cruising Utopia: The Then and There of Queer Futurity. Nueva York: NYU Press, 2009.

Perlonguer, N. (1988). El fantasma del sida. Buenos Aires: Punto Sur.

Rancière, J. (2006). Política, policía, democracia. Santiago de Chile: LOM.

Salas, F. (Del 1 al 8 de mayo de 1989). Entrevista: "Las Yeguas del apocalipsis. Cauce.

Taylor, D. (agosto 2007). Hacia una definición del performance. Performanceologia: Todo sobre arte del performance y performancistas. Recuperado de http://performancelogia. blogspot.com/2007/08/hacia-una-definicin-de-performance.html

Yeguas del Apocalipsis. (2015). Santiago de Chile: Consejo Nacional de la Cultura y las artes. http://www.yeguasdelapocalipsis.cl/biografia/ 